\title{
Representações sociais de ciclos de aprendizagem entre estudantes de pedagogia
}

\author{
Laeda Bezerra Machado \\ Suelen Batista Freire \\ Universidade Federal de Pernambuco
}

\section{Resumo}

Este artigo tem como objetivo delinear o possível núcleo central das representações sociais de ciclos de aprendizagem entre estudantes de Pedagogia. 0 referencial de base foi a teoria das representações sociais, particularmente a abordagem estrutural proposta por Abric (1998). Realizouse a pesquisa com 200 estudantes em diferentes estágios de formação na Universidade Federal de Pernambuco. 0 procedimento de coleta foi a técnica de associação livre, cujas palavras resultantes foram tratadas com o software EVOC. Os resultados sugerem que os estudantes estão construindo representações sociais que se distanciam dos princípios norteadores da proposta dos ciclos de aprendizagem.

Palavras-chave: Representações sociais. Ciclos de aprendizagem. Estudantes de pedagogia. 


\section{Social representations of learning cycles among undergraduates in education}

This article aims to describe the possible central nucleus of the social representations of learning cycles among students of education. The basic reference was the theory of social representations, particularly the structural approach proposed by Abric (1998). The research was conducted with 200 students in different stages of the course at the Federal University of Pernambuco. The collection procedure was the technique of free association, whose resulting words were processed with EVOC software. The results suggest that the students are constructing social representations that differ from the guiding principles of the proposal of learning cycles.

Keywords: Social representations. Learning cycles. Undergraduates in Education.

\section{Representaciones sociales de ciclos de aprendizaje entre estudiantes de pedagogía}

En este artículo se pretende esbozar el posible núcleo central de las representaciones sociales de ciclos de aprendizaje entre estudiantes de pedagogía. La referencia básica fue la teoría de las representaciones sociales, particularmente el enfoque estructural propuesto por Abric (1998). La investigación se realizó con 200 estudiantes en diferentes pasos del curso en la Universidad Federal de Pernambuco. El procedimiento de extracción fue la técnica de asociación libre, cuyas palabras resultantes fueron tratadas con el software EVOC. Los resultados sugieren que los estudiantes construyen representaciones sociales que están lejos de los principios rectores de la propuesta de ciclos de aprendizaje.

Palabras-clave: Representaciones sociales. Ciclos de aprendizaje. Estudiantes de pedagogía. 


\section{Introdução}

Os ciclos de aprendizagem constituem um esforço das políticas públicas no sentido de conter a distorção idade/série, cujos índices atingiram proporções muito altas até os anos 1990 no país. De acordo com Machado e Aniceto (2010), dados do MEC/INEP (2003) apontavam que, dos 35,7 milhões de alunos matriculados no ensino fundamental, 8,46 milhões estavam em defasagem idade/série. A organização do processo pedagógico em ciclos apresenta-se, portanto, como uma forma complexa de democratização da escola.

Um de seus princípios é tomar a aprendizagem como um processo contínuo, evitando-se interrupções. Também merece destaque a avaliação, que não mais aparece como classificatória, apresentando-se numa perspectiva formativa. E, para dar suporte a esta visão de avaliação, a proposta sugere uma pedagogia diferenciada, ajustando-se às necessidades dos educandos e atendendo-os de acordo com suas especificidades. Além disso, não ocorre a reprovação anual. Nessa perspectiva, os mecanismos e formas de retenção variam entre os sistemas, alguns chegando até a eliminar a retenção completamente. No caso da proposta da cidade do Recife, local onde os dados da pesquisa foram coletados, o ensino fundamental de nove anos está organizado em quatro ciclos e só é permitida a retenção do aluno ao final de cada ciclo.

Como vantagens dos ciclos de aprendizagem, Mainardes (2009) aponta: possibilitam romper com a lógica seriada (considerada nociva para a manutenção da democratização do ensino); fomentam a reflexão profunda de homem, mundo, educação etc.; oportunizam mais tempo para a aprendizagem; substituem a avaliação classificatória pela avaliação formativa; vão em direção à garantia da permanência dos alunos que seriam potencialmente excluídos da escola; promovem o convívio de estudantes com idades semelhantes; e sua proposta ainda prevê oferta de estudos complementares, diminuição do número de alunos por classe, aquisição de materiais pedagógicos e investimentos na formação permanente dos professores.

A proposta de ciclos para a Rede Municipal do Recife, campo da pesquisa, propõe reorganizar o espaço, o tempo escolar e a prática pedagógica, respeitando a diversidade e os diferentes tempos que o aluno deve ter para aprender (Recife, 2003). Feitas essas considerações, é lançado como objetivo para este estudo delinear o possível núcleo central das representações sociais de estudantes do curso de Pedagogia da Universidade Federal de Pernambuco (UFPE) sobre ciclos de aprendizagem. 


\section{Algumas considerações sobre a teoria das representações sociais}

Embora os ciclos de aprendizagem venham sendo implantados na cidade do Recife desde 2001, não constituem um tipo de organização escolar universal e revelam-se como polêmicos nos meios escolares devido às mudanças que sugerem ou provocam. Assim, é justificável que sejam estudados a partir das representações sociais, uma vez que essa abordagem tem se debruçado sobre objetos e eventos que mobilizam e reconfiguram as relações sociais.

A teoria das representações sociais foi apresentada pela primeira vez por Sèrge Moscovici, em 1961, e tem sido desenvolvida e aplicada ao longo dos anos por diversos autores e em variados campos. As representações sociais são conhecimentos elaborados e compartilhados socialmente, que se refletem nos discursos e práticas dos grupos e na forma como eles interpretam, explicam e justificam a realidade. De acordo com Machado (2007, p. 7), "são produtos de experiências acumuladas por um processo histórico dos fatos, os quais constituem os sistemas cognitivos das pessoas".

As representações sociais não se reduzem à opinião de um grupo sobre determinado assunto ou à imagem construída de algo em sua mente. Muito mais do que isso, as representações sociais, de acordo com Alves-Mazzotti (1994), constituem:

Teorias coletivas sobre o mundo real, sistemas que têm uma lógica e uma linguagem particulares, uma estrutura de implicações baseada em valores e conceitos, e que determinam o campo das comunicações possíveis, dos valores e das ideias compartilhadas pelos grupos e regem, subsequentemente, as condutas desejáveis ou admitidas. (Alves-Mazzotti, 1994, p. 62)

Em 1976, Jean Claude Abric vem ampliar a versão original da teoria das representações sociais, ao apresentar a Teoria do Núcleo Central (TNC), também chamada de abordagem estrutural. Conforme Abric (1998), toda representação social é organizada internamente por um núcleo central e um sistema periférico, em seu entorno. Esse autor defende que, no interior de uma representação, alguns elementos ocupam posições distintas e exercem diferentes funções.

De acordo com essa abordagem, na estrutura da representação social, a base comum das representações de um grupo seria o núcleo central, que é o que mantém, de certa forma, a homogeneidade do grupo. Assim sendo, é condição, para que dois ou mais grupos tenham as mesmas representações de dado objeto, a partilha do mesmo núcleo central. Foi utilizada na pesquisa a abordagem estrutural, que oportunizou compreender a estrutura das representações sociais de estudantes de pedagogia da UFPE sobre ciclos de aprendizagem, focalizando especificamente no núcleo central dessas representações. 


\section{Metodologia}

Fundamentado na teoria das representações sociais, o estudo do qual resultou este artigo é de natureza qualitativa e procura delinear o possível núcleo central das representações sociais de ciclos de aprendizagem dos estudantes de pedagogia da UFPE. Para isso, fez-se uso da técnica de associação livre de palavras.

\section{Procedimento de coleta de informações: o teste de associação livre de palavras}

Como colocam Oliveira et al (2005), a técnica de associação livre de palavras consiste em solicitar aos sujeitos que falem ou registrem, de modo livre e rápido, palavras ou expressões que lhes vêm imediatamente à lembrança mediante a apresentação de um estímulo. 0 estímulo pode ser uma palavra impressa, um objeto, uma figura, entre outros. As evocações dos sujeitos permitem colocar em evidência os universos semânticos relacionados a determinado conteúdo. A técnica pode favorecer a obtenção de um material mais espontâneo junto aos sujeitos da pesquisa.

\section{Campo empírico}

O campo de pesquisa foi o Centro de Educação da UFPE. A escolha ateve-se aos critérios: abrigar o maior curso de pedagogia do estado de Pernambuco, com entrada anual de 250 estudantes, e apresentar uma boa classificação no Exame Nacional de Desempenho de Estudantes (Enade), um dos instrumentos avaliativos complementares do Sistema Nacional de Avaliação da Educação Superior (Sinaes). A posição privilegiada do curso no estado permite supor que seu projeto formativo estaria sintonizado com as demandas exigidas pelas políticas educacionais no que tange aos novos profissionais no contexto atual.

\section{Participantes}

Participaram desta pesquisa 200 estudantes do curso de pedagogia, cursando do segundo ao nono (últimol período, nos três turnos oferecidos pela UFPE (matutino, vespertino e noturno). Os estudantes do primeiro período não foram incluídos tendo em vista o fato de que estão chegando ao curso e, possivelmente, não tiveram tempo para conhecer sobre os ciclos de aprendizagem no curso.

Dos 200 estudantes, 112 (56\%) afirmaram ter tido algum tipo de experiência prática como estagiários ou professores em escolas públicas e/ou particulares. A maioria dos sujeitos foi composta de pessoas do gênero feminino (dos 200 sujeitos, 
apenas dez eram do gênero masculino, isto é, apenas $5 \%$ ).

Com relação a faixa etária dos sujeitos, a média de idade era de 25,77 anos. A maioria dos estudantes ficou compreendida entre 18 e 27 anos de idade, perfazendo $73,5 \%$. Os sujeitos com idades entre 28 e 37 anos corresponderam a $21,5 \%$ e aqueles com idades entre 38 e 47 anos constituíram $5 \%$. A Tabela 1, a seguir, traz esses dados de maneira sintetizada:

Tabela 1 - Faixa etária dos estudantes que responderam aos questionários.

\begin{tabular}{c|c|c}
\hline Faixa etária & $\boldsymbol{f}$ & $\mathbf{\%}$ \\
\hline 18 a 22 & 75 & $37,50 \%$ \\
\hline 23 a 27 & 72 & $36,00 \%$ \\
\hline 28 a 32 & 23 & $11,50 \%$ \\
\hline 33 а 37 & 20 & $10,00 \%$ \\
\hline 38 a 42 & 04 & $02,00 \%$ \\
\hline 43 a 47 & 06 & $03,00 \%$ \\
\hline TOTAL & $\mathbf{2 0 0}$ & $\mathbf{1 0 0 , 0 0 \%}$ \\
\hline
\end{tabular}

Fonte: dados da pesquisa

Quanto à aplicação do teste de associação livre, antes da coleta de dados ser iniciada, a previsão era de que os testes fossem aplicados com dez estudantes de cada turma. Isso não foi possível devido à baixa quantidade de estudantes matriculados no último período do curso (nono período) no turno da tarde lapenas 16 matriculados). Parte desses estudantes foi localizada, entretanto alguns não concordaram em participar da pesquisa.

Responderam ao teste de associação livre 88 estudantes do turno da manhã Itodos os períodos do turno matutino contaram com a participação de dez estudantes, com exceção do quarto e sexto períodos, que tiveram frequência de 11 e 17 estudantes, respectivamente). No turno da tarde, participaram 32 estudantes ${ }^{1}$. Com exceção do nono período do turno da tarde, que teve apenas dois estudantes participando da pesquisa, os demais períodos tiveram dez estudantes cada. No turno da noite, todas as turmas tiveram dez estudantes participando da pesquisa, perfazendo um total de 80 participantes. Somados os alunos dos turnos matutino, vespertino e noturno, obteve-se o total de 200 sujeitos.

1. No curso de Pedagogia da UFPE, não são abertas vagas para o turno da tarde na primeira entrada anual. Apenas na segunda entrada são ofertadas vagas para esse turno. Por esse motivo é que não aparecem os períodos pares $\left(2^{\circ}, 4^{\circ}, 6^{\circ}\right.$ e $\left.8^{\circ}\right)$ nos dados do turno da tarde. 


\section{Procedimento de coleta}

0 instrumento de coleta foi um questionário com cinco questões. As duas primeiras tiveram o intuito de identificar os sujeitos em termos de período, turno, idade, gênero e saber se já haviam tido experiência profissional na área da educação. A terceira questão era o teste de associação livre de palavras propriamente dito. Nesta parte, os sujeitos deveriam escrever, de maneira imediata, as cinco primeiras palavras que lhes viessem à mente ao pensar em ciclos de aprendizagem. A quarta questão solicitava que os estudantes circulassem, dentre as cinco palavras que haviam escrito, aquela que consideravam a mais importante. E a última questão pedia que escrevessem uma breve justificativa para a escolha daquela palavra apontada como a mais importante.

\section{Procedimento de análise}

Uma vez coletados os dados, as palavras resultantes da técnica de associação livre foram processadas através do software Ensemble de programmes permettant l'analyse des evocations (EVOC), versão 2000, criado por Pierre Vergès. Esse software permite dois tipos de análises de evocações: a construção do quadro de quatro casas e a análise de similitude (Oliveira et al, 2005). Para esta pesquisa, interessou a construção do quadro de quatro casas, no qual as palavras resultantes da associação livre são distribuídas com base na saliência da representação.

A interpretação do quadro de quatro casas, conforme Oliveira et al (2005), sugere que cada casa, ou quadrante, corresponde a aspectos estruturantes da representação. No quadrante superior esquerdo, localizam-se as palavras que constituem, muito provavelmente, o núcleo central da representação, e, nos demais quadrantes (superior direito, inferior esquerdo e inferior direito), o sistema periférico. Cumpre ressaltar que, nos limites deste artigo, o foco se restringiu ao conteúdo do núcleo central, localizado no quadrante superior esquerdo do quadro de quatro casas.

De acordo com Lima (2009), o EVOC possibilita organizar as palavras no quadro de quatro casas associando a frequência à ordem média de evocação (OME) dessas palavras. Sua finalidade é "[...] tomar como prováveis elementos centrais os componentes mais frequentes e prontamente evocados tendo como referência a média das frequências (MF) e a média das ordens médias de evocação (MOME)." (Lima, 2009, p. 155)

Dos 16 programas que constituem este software, foram utilizados cinco: Lexique, Trievoc, Nettoie, Rangmote Rangfrq. Os dois primeiros programas prepararam o arquivo para o terceiro programa, Nettoie, que permite a interferência do pesquisador. Nesse programa, foi verificado se alguma palavra continha erros de 
ortografia e foram condensadas as palavras que se repetiam ou tinham o mesmo significado. Por exemplo, foram evocadas as palavras "aluno" (dez vezes), "alunos" (duas vezes), "discente" (uma vez), “educandos" (uma vez) e "estudante” (uma vez). Tendo em vista que essas palavras têm significado similar, onde havia qualquer uma delas, substituiu-se por "aluno", que, deste grupo de palavras utilizadas como exemplo, é aquela com maior número de evocações. Sendo assim, a palavra "aluno" obteve frequência igual a 15.

Esta etapa de condensar palavras com significado similar exigiu reflexão porque havia a preocupação de que fossem formados grupos distintos e consistentes de palavras, de forma mais fiel possível aos dados coletados. Depois das palavras terem sido agrupadas pelo pesquisador, os dados continuaram a ser processados no programa Rangmot e, em seguida, no programa Rangfrq, que, finalmente, distribuiu as palavras no quadro de quatro casas. No Quadro 1, é exposto o quadro de quatro casas gerado pelo EVOC:

Quadro 1 - Quadro de quatro casas gerado pelo EVOC²

\begin{tabular}{|l|c|c|l|l|l|}
\hline \multicolumn{3}{|c|}{ F >= 10 /OME < 2,5 } & \multicolumn{3}{c|}{ F >= 10 /OME >= 2,5 } \\
\hline Palavras evocadas & $\boldsymbol{f}$ & $\mathbf{0 M E}$ & Palavras evocadas & $\mathbf{f}$ & $\mathbf{0 M E}$ \\
\hline Aprendizagem & 37 & 2,405 & Aluno & 15 & 2,600 \\
\hline Aprovação & 19 & 2,316 & Avaliação & 29 & 2,517 \\
\hline Confuso & 19 & 2,211 & Compromisso & 14 & 2,929 \\
\hline Conhecimento & 26 & 2,000 & Descaso & 13 & 2,692 \\
\hline Conteúdo & 10 & 2,400 & Desorganização & 11 & 2,909 \\
\hline Continuidade & 17 & 2,412 & Didática & 13 & 2,692 \\
\hline Desenvolvimento & 20 & 2,250 & Falho & 21 & 3,095 \\
\hline Déficit & 10 & 2,100 & Organização & 11 & 3,000 \\
\hline Ensino & 11 & 2,455 & & & \\
\hline Etapas & 15 & 2,267 & & & \\
\hline Mudança & 14 & 2,357 & & & \\
\hline Oportunidade & 19 & 1,895 & & & \\
\hline Professor & 14 & 1,929 & & & \\
\hline
\end{tabular}

2. Frequência mínima: 5,0; média de frequência (MF): 10,0 e média das ordens médias de evocação (MOME): 2,5 . 


\begin{tabular}{|c|c|c|c|c|r|}
\hline \multicolumn{2}{|c|}{ F < 10 /OME < 2,5 } & \multicolumn{2}{c|}{ F < 10 /OME >= 2,5 } \\
\hline Palavras evocadas & $\boldsymbol{f}$ & $\mathbf{0 M E}$ & Palavras evocadas & $\mathbf{f}$ & $\mathbf{0 M E}$ \\
\hline Alfabetização & 07 & 1,714 & Acompanhamento & 06 & 2,833 \\
\hline Atraso & 05 & 2,200 & Atenção & 09 & 2,889 \\
\hline Avanço & 06 & 1,833 & Comunidade & 06 & 3,333 \\
\hline Construção & 09 & 2,333 & Diversidade & 05 & 2,600 \\
\hline Desconhecido & 07 & 2,429 & Enrolação & 09 & 3,111 \\
\hline Dificuldade & 08 & 2,250 & Formação & 07 & 3,000 \\
\hline Divisão & 05 & 2,000 & Grupo & 07 & 2,857 \\
\hline Experiência & 06 & 2,333 & Idade & 08 & 3,125 \\
\hline Imitação & 05 & 2,400 & Interação & 09 & 2,667 \\
\hline Não aprendizagem & 06 & 2,333 & Objetivos & 05 & 3,600 \\
\hline Processo & 08 & 2,250 & Planejamento & 08 & 3,125 \\
\hline Reflexão & 06 & 2,167 & Prática & 06 & 2,833 \\
\hline Reprovação & 08 & 2,125 & Respeito & 05 & 2,800 \\
\hline Troca & 05 & 2,000 & Retenção & 08 & 2,500 \\
\hline & & & Tempo & 08 & 2,500 \\
\hline
\end{tabular}

Fonte: dados da pesquisa

As palavras que tiveram frequência inferior a cinco, isto é, que foram lembradas por menos de cinco pessoas, não apareceram no quadro. A definição do corte para a exclusão é um procedimento realizado normalmente pelo software EVOC. Cumpre ressaltar também que, devido ao fato de cada sujeito ter escrito cinco palavras através da técnica de associação livre, a ordem de evocação de cada palavra só pode variar de um a cinco. A primeira ordem indica que a palavra foi a mais prontamente evocada no grupo de cinco palavras e a quinta ordem revela que a palavra foi evocada por último. A ordem média de evocação (OME), que é apresentada ao lado de cada palavra no quadro de quatro casas, constitui a média de todas as ordens de evocação que aquela referida palavra atingiu.

A média das frequências e a média das ordens médias de evocação (MOME) são informadas pelo software (quais sejam: dez e 2,5, respectivamente). Os cortes que determinaram onde cada palavra ficou localizada basearam-se nessas duas médias. No quadro de quatro casas, a frequência e a ordem média de evocação das palavras determinam sua localização nesse quadro. Assim sendo, as palavras do quadrante superior esquerdo (suposto núcleo central) tiveram frequência superior ou igual a dez e OME inferior a 2,5. Trata-se do quadrante cujas palavras tiveram 
maior frequência e foram mais prontamente evocadas pelos estudantes. 0 núcleo central, de acordo com a abordagem estrutural, é construído pelos elementos mais fortes, resistentes e estáveis de uma representação.

\section{Resultados e discussão}

Nos limites deste artigo, conforme já foi dito, será explorado exclusivamente o núcleo central. De acordo com o Quadro 1, constituem muito provavelmente o núcleo central das representações sociais de ciclos de aprendizagem dos estudantes de pedagogia da UFPE as palavras: "aprendizagem", “aprovação", "confuso", “conhecimento", “conteúdo", “continuidade”, "desenvolvimento", "déficit”, "ensino", "etapas", “mudança”, "oportunidade" e "professor".

Dessas 13 palavras, a primeira que aparece (respeitando-se a ordem alfabética) como elemento do possível núcleo central é “aprendizagem”. Essa palavra foi evocada 37 vezes e sua ordem média de evocação foi igual a 2,405. A palavra "aprendizagem" foi a que teve maior frequência de todas as palavras evocadas e sua OME foi mediana, a terceira mais alta entre os elementos que compõem 0 quadrante superior esquerdo.

A respeito dessa palavra, destaca-se que os ciclos visam enfatizar aspectos como a progressão das aprendizagens. Para que haja essa progressão, deve existir o trabalho em equipe (dando unidade ao ciclo), a avaliação formativa e a pedagogia diferenciada, além da continuidade da aprendizagem. Esses aspectos preconizados pela proposta dos ciclos (Recife, 2003) parecem estar ancorados nas representações dos estudantes de pedagogia, como pode ser observado em algumas das justificativas escritas pelos sujeitos nos questionários:

Os ciclos de aprendizagem servem para levar oportunidade da construção do conhecimento junto ao aluno, ou seja, uma troca de aprendizagem. (038/3t/21a/F/ $\mathrm{CE})^{3}$

[...] a aprendizagem tem certo tempo para se desenvolver, os conteúdos podem ser trabalhados durante certo tempo e pode-se verificar se o aluno desenvolveu certa competência para prosseguir sua trajetória escolar. $\left(103 / 6^{\circ} \mathrm{m} / 22 \mathrm{a} / \mathrm{F} / \mathrm{CE}\right)$

Entretanto, podemos notar que o termo "aprendizagem", vez por outra, foi pensado como o ideal, o que deveria acontecer, mas que, de fato, não acontece. Exemplo disso é a justificativa de um sujeito, exposta no trecho que segue:

3. 0 código significa, respectivamente, número do questionário, período que o estudante cursava, turno l“m” para manhã, "t" para tarde e " $n$ " para noite), idade, gênero e "CE" para "com experiência como professor ou estagiário em escola" ou "SE" para "sem experiência". 
0 foco do sistema de ciclos é viabilizar a aprendizagem... [Mas,] em minha opinião, não mudou nada, só mudou a nomenclatura. 0 sistema de ciclos foi implantado baseado nos franceses, cuja realidade é totalmente diferente. $\left(157 / 8^{\circ} \mathrm{m} / 26 \mathrm{a} / \mathrm{F} / \mathrm{CE}\right)$

Outro termo que aparece no possível núcleo central das representações sociais de estudantes de pedagogia sobre os ciclos de aprendizagem é "aprovação", evocado 19 vezes e com OME 2,316. Embora a palavra tenha um tom de positividade, quando os estudantes têm oportunidade de justificar a sua escolha, utilizam o termo "aprovação" para falar do que consideram negativo na proposta, conforme pode ser ilustrado pelas justificativas dos sujeitos:

Infelizmente, o ciclo hoje serve apenas para evitar o grande nível de repetência. $\left(115 / 6^{\circ} \mathrm{n} / 26 \mathrm{a} / \mathrm{F} / \mathrm{CE}\right)$

Os ciclos de aprendizagem centram-se na promoção automática dos alunos. Em minha opinião, isso é um engodo criado para reduzir os índices de reprovação, sem considerar a aprendizagem real dos alunos. Eles passam sem saber e a maioria deles não está nem aí para o ensino, só querem saber do dinheiro do Bolsa-Escola . $\left(186 / 6^{\circ} \mathrm{m} / 27 \mathrm{a} / \mathrm{F} /\right.$ CE)

A não retenção anual é um dos pontos da proposta, que enseja tornar a escola mais democrática, opondo-se à lógica seriada. Como pode ser observado, para o grupo pesquisado, essa possibilidade é encarada como algo indesejável. Aliás, parte do grupo também considera os ciclos de aprendizagem "confusos", tendo evocado essa palavra 19 vezes, com OME 2,211. De forma geral, alegam que a confusão se dá em três sentidos. 0 primeiro diz respeito ao fato de acreditarem que a proposta não é bem explicada, nem haveria iniciativas consistentes por parte da Secretaria Municipal de Educação para divulgá-la. O segundo decorre das várias dúvidas que acumulam sobre a proposta, como, por exemplo, “o que se deve fazer com os alunos que não avançaram no aprendizado"? $1052 / 4^{\circ} \mathrm{m} / 23 \mathrm{a} /$ F/SE). E, por último, destacam também o distanciamento entre o que é proposto e as práticas na escola. As referências ao termo "confusos" podem ser ilustradas nos trechos abaixo:

Demorei muito para entender e compreender essa dinâmica de ciclos de aprendizagem. E, por esse motivo, considero confuso. $\left(027 / 3^{\circ} \mathrm{m} / 19 \mathrm{a} / \mathrm{F} / \mathrm{SE}\right)$

[...] os ciclos tiveram como um dos pontos principais o combate à evasão escolar, porém atrela este combate à não repetência ou à diminuição dela. Não acredito em avanços com este tipo de atrelamento. $\left(191 / 9^{\circ} \mathrm{n} / 34 \mathrm{a} / \mathrm{M} / \mathrm{SE}\right)$

0 que eu vi de teoria sobre ciclos é totalmente diferente do que tenho vivenciado na rede [de ensino]. Portanto, "confuso". (193/90n/28a/M/CE) 
Outra palavra situada no possível núcleo central dessa representação é "conhecimento", que foi evocada 26 vezes e obteve OME 2,000. Para os estudantes, o conhecimento é entendido como algo desejável, "a base de tudo e é fundamental para o exercício de qualquer atividade" $\left(009 / 2^{\circ} \mathrm{m} / 19 \mathrm{a} / \mathrm{F} / \mathrm{SE}\right)$. Isso fica ainda mais claro quando ao lado da justificativa a seguir:

Eu escolhi a palavra conhecimento devido à importância que ele tem na vida de todos os indivíduos. Através do conhecimento é possível o indivíduo crescer intelectualmente, materialmente e socialmente. $\left(089 / 5^{\circ} \mathrm{t} / 25 \mathrm{a} / \mathrm{F} / \mathrm{CE}\right)$

0 termo "conteúdo" também vem prontamente à mente dos sujeitos quando pensam em ciclos. A palavra foi evocada dez vezes e alcançou OME 2,400. Para os sujeitos, "é preciso selecionar bem os conteúdos que serão trabalhados e escolher o melhor método para transmiti-lo" (183/50t/25a/F/SE). E, através de como é trabalhado o conteúdo, "poderemos saber como melhor ajudar o aluno, se o mesmo apresenta alguma dificuldade. Para assim fazer um planejamento que seja adequado para o tema". (184/5ํt/28a/F/CE)

A palavra "continuidade" foi evocada 17 vezes e contou com OME 2,412, isto é, se comparada às demais palavras do quadrante superior esquerdo, trata-se de uma palavra com frequência mediana e a segunda maior OME do suposto núcleo central. 0 grupo pesquisado entende que os ciclos de aprendizagem são capazes de garantir essa continuidade, como fica claro nos trechos transcritos a seguir:

[...] o ciclo tem como objetivo dar continuidade no processo de ensino/aprendizagem [...] $\left(015 / 2^{\circ} \mathrm{n} / 20 \mathrm{a} / \mathrm{F} / \mathrm{CE}\right)$

É uma oportunidade que os alunos têm para atingirem de forma contínua um nível de aprendizagem que se espera [...] $\left(029 / 3^{\circ} \mathrm{m} / 18 \mathrm{a} / \mathrm{F} / \mathrm{SE}\right)$

A continuidade das aprendizagens é um princípio preconizado pela proposta de ciclos. Segundo a proposta, eles permitem a continuidade da aprendizagem, dando melhor flexibilidade no que se refere ao atendimento diferenciado aos alunos. Alavarse (2009) procura desconstruir o argumento de que para o aluno é importante repetir a série em que não se conseguiu aprender algo. As críticas do referido autor com relação a esse pensamento centram-se no fato de que, geralmente, novas alternativas e formas de aprender não têm sido garantidas aos estudantes. A repetição em si do ano letivo anterior não contribuiria para se aprender aquilo que não se teve a oportunidade.

Outra palavra localizada no possível núcleo central dessa representação é "desenvolvimento". Essa palavra foi evocada 20 vezes la terceira maior frequência de todas as palavras lembradas) e obteve OME 2,250. Para os sujeitos, o desenvolvimento caminha em paralelo com a aprendizagem, “independente do 
caminho, meio ou método" $\left(002 / 2^{\circ} \mathrm{m} / 20 \mathrm{a} / \mathrm{F} / \mathrm{SE}\right)$. Nesse sentido, para o grupo, os ciclos proporcionam o desenvolvimento de muito mais do que os conhecimentos e conteúdos escolares. Proporcionam o desenvolvimento de aspectos relacionados ao contexto social dos indivíduos. Afirma um dos sujeitos:

[...] acredito que desenvolvimento está associado não apenas a conteúdos ou a apreensão de conteúdos, mas ao contexto real e social. (048/3ํㅡ/27a/F/CE)

Mas nem todos pensam assim. Para alguns, ainda existem muitas deficiências a serem superadas nos ciclos de aprendizagem. A palavra "déficit" foi evocada dez vezes e alcançou OME 2,100 la quarta menor OME desta casa do quadro gerado pelo EVOCl. Os sujeitos, ao se referirem a "déficit", novamente retomaram questões relacionadas ao que é proclamado na proposta e ao que ocorre na prática. São mencionados pelo grupo problemas/incoerências em relação à avaliação dos alunos e a retenção ainda é vista como necessária, o que pode ser observado nos seguintes trechos:

[A palavra déficit] resume bem como se encontra o ensino nas escolas públicas. Não há um processo avaliativo que auxilie [na] aprendizagem. Os alunos vão avançando de ano sem possuir as condições básicas de conhecimento para enfrentar o ano seguinte. $\left(151 / 8^{\circ} \mathrm{m} / 22 \mathrm{a} / \mathrm{F} / \mathrm{CE}\right)$

[...] ao invés de obedecer ao que rege a proposta, [na prática, se] mascara uma metodologia de avaliação, correção de faixa etária e aprovação. (181/90t/27a/F/CE)

Essa mesma associação de ciclos a fracasso e déficit na aprendizagem já foi constatada em estudos anteriores, junto a professores da Rede Municipal do Recife (Machado, 2007; Machado \& Aniceto, 2010; Aniceto, 2011).

A palavra "ensino" também veio prontamente à mente dos sujeitos, tendo sido evocada 11 vezes e sua OME atingiu 2,455. Os sujeitos se referiram ao ensino como importante, "pois é através dele que se encontram as ações do educador, que não são unicamente pedagógicas, mas também ideológicas" $\left(074 / 5^{\circ} \mathrm{m} / 22 \mathrm{a} / \mathrm{F} / \mathrm{CE}\right)$. A escola tem como principal função o ensino, em interdependência com o ato de aprender. Se não há aprendizagem, não há ensino. Logo, caso os alunos não aprendam o que se espera, a escola não está cumprindo essa importante tarefa. Os estudantes de pedagogia da UFPE chamam atenção para a importância desse papel da escola.

Outra palavra que se localiza no suposto núcleo central é "etapas", com 15 evocações e OME 2,267. Para os sujeitos, as aprendizagens se desenvolvem em etapas ou fases. Tendo em vista que, no sistema de organização escolar em ciclos, as etapas não são estanques ou partidas em anos letivos distintos, cabe ao professor ficar atento às necessidades educacionais de seus alunos. A justificativa 
apresentada a seguir ilustra esse pensamento:

[...] o ciclo de aprendizagem se dá através de etapas, que foram pensadas para acompanhar os alunos no processo de ensino/aprendizagem. (091/5n $/ 23 a / F / C E)$

Conforme consta no quadrante superior esquerdo do quadro, a palavra "mudança" aparece evocada 14 vezes, com OME 2,357. A partir das justificativas dos sujeitos, podemos observar que este grupo representa os ciclos como algo novo e, em suas justificativas, consideram que é muito cedo para se posicionar positiva ou negativamente, como pode ser visto:

[...] com o novo sistema de ciclos, nos dá uma primeira impressão de mudança/ transformação, mesmo que não saibamos se boas ou não. $\left(077 / 5^{\circ} \mathrm{m} / 21 \mathrm{a} / \mathrm{F} / \mathrm{CE}\right)$

Embora os ciclos de aprendizagem tenham sido implantados na Rede Municipal do Recife desde 2001, os dados sugerem que os referenciais desse grupo de estudantes de pedagogia ainda estão muito próximos do sistema de seriação. Tal sistema, muito provavelmente foi o modelo de organização escolar que vivenciaram enquanto alunos na educação básica.

Outra palavra situada no suposto núcleo central de ciclos foi "oportunidade", tendo sido evocada 19 vezes e sua OME foi 1,895. Embora a frequência desta palavra não tenha sido tão alta, observa-seque foi a palavra com menor OME no conjunto do suposto núcleo central e a terceira palavra com melhor média de evocação no conjunto de todas as palavras evocadas. Isto é, apesar de não ter sido uma das palavras mais lembradas do suposto núcleo central, quando evocada, foi considerada uma palavra de extrema importância pelos sujeitos. Pelo que sugerem as justificativas, para os estudantes de Pedagogia, "oportunidade" significa o fim da reprovação. Nessa nova organização, os alunos têm mais chances de se desenvolverem para além de um ano letivo. Os estudantes reconhecem que os ciclos de aprendizagem constituem um esforço para prevenir o fracasso escolar, conforme transcrito:

[...] com os ciclos de aprendizagem, o aluno tem a oportunidade de desenvolver os saberes que ainda não tinha aprendido sem ter que cursar novamente a mesma série. $\left(005 / 2^{\circ} \mathrm{m} / 19 \mathrm{a} / \mathrm{F} / \mathrm{SE}\right)$

Os ciclos de aprendizagem vêm, de certo modo, suprir as necessidades dos alunos, sendo uma oportunidade para que permaneçam por mais tempo na escola, já que não ficam retidos nas primeiras séries. $\left(176 / 9^{\circ} \mathrm{m} / 24 \mathrm{a} / \mathrm{F} / \mathrm{SE}\right)$

0 termo "professor" também compõe o suposto núcleo central de ciclos de aprendizagem. A referida palavra foi evocada 14 vezes e possui OME 1,929 la segunda menor OME do quadrante superior esquerdo). Pelo exposto, o termo 
"professor" foi associado a ciclos como o ator mais importante do processo de ensino-aprendizagem. Embora não especifiquem a forma de organização escolar, para os estudantes, o professor é fundamental para o desenvolvimento e aprendizagem dos alunos, como pode ser visto no trecho que segue:

[...] acredito que o docente é o ator principal na promoção de uma aprendizagem de qualidade e, para tanto, precisa se manter atualizado e buscar promover o aprendizado dos alunos. $\left(068 / 4^{\circ} \mathrm{n} / 35 \mathrm{a} / \mathrm{F} / \mathrm{SE}\right)$

\section{Considerações finais}

Em linhas gerais, o possível núcleo central das representações sociais de ciclos de aprendizagem dos estudantes de pedagogia da UFPE apresenta saliência em elementos favoráveis e desfavoráveis à proposta. Como favoráveis, destacamse: “aprendizagem", “continuidade", "desenvolvimento" e "oportunidade" loportunidade no sentido de não haver reprovação, de modo que o aluno não fica retidol. Esses aspectos estão presentes nos pressupostos dos ciclos.

Como desfavoráveis, constituem as representações desse grupo os elementos: “aprendizagem”, “aprovação”, “confusos” e "déficits”. Convém lembrar que o termo "aprendizagem" aparece tanto como elemento favorável quanto como elemento desfavorável aos ciclos, tendo em vista que esses estudantes evocaram a palavra associada a elementos diferentes. Por um lado, existe, de fato, aprendizagem no sistema de ciclos. Por outro, a aprendizagem deveria acontecer, mas não acontece em virtude das fragilidades do contexto de implantação e efetivação da proposta na prática.

Também "aprovação", termo que denota positividade, aparece com uma conotação negativa. A aprovação (de um ano escolar para outro) de forma contínua, sem interrupções, é representada como algo não desejado, que impede os alunos de aprenderem o que não conseguiram antes, gerando o acúmulo das aprendizagens.

"Confusos", na perspectiva dos estudantes, corresponde à confusão que eles acreditam girar em torno da proposta. Isso acontece, seja devido aos pressupostos dos ciclos não serem amplamente divulgados e esclarecidos pelos sistemas, seja em razão dos ciclos não fornecerem respostas a problemas gerais vividos na escola ou por não se tornarem efetivos na prática dos docentes (por dificuldades de compreensão ou por discordância da propostal.

Os déficits são tomados, também, como deficiências ou lacunas dos ciclos de aprendizagem. Os estudantes acreditam que a proposta dos ciclos, por si só, não responde a todos os problemas e desafios vivenciados no dia a dia escolar. Além desses elementos, os sujeitos ainda chamaram atenção para a importância de outros aspectos, quais sejam: busca pelo conhecimento, escolha de conteúdos 
adequados, modo de conduzir o ensino, etapas da aprendizagem, mudanças ocorridas na forma de compreensão da escola e o papel do professor.

Em suma, os ciclos constituem uma proposta de democratização da escola, buscando garantir o acesso e a permanência. No entanto, os futuros professores revelam estar construindo uma representação de ciclos de aprendizagem que se distancia dos princípios norteadores da proposta. Seja por discordâncias ou por dificuldades de compreensão. No caso das dificuldades de compreensão, tais representações apontam para que os cursos de pedagogia, reconhecendo a importância da proposta de ciclos de aprendizagem que se consolida na rede de ensino, tomem-na como objeto de discussão em seus projetos formativos, uma vez que os futuros professores poderão vir a atuar nessa forma de organização curricular.

\section{Referências}

ABRIC, Jean Claude.Abordagem estrutural das representações sociais. Trad. Pedro Humberto de Faria. In: MOREIRA, A S. P; OLIVEIRA, D. C. Estudos interdisciplinares de representação social. Goiânia-GO: Editora AB, 1998. p. 27-38.

ALAVARSE, Ocimar Munhoz. A organização do ensino fundamental em ciclos: algumas questões. Revista brasileira de educação. Rio de Janeiro-RJ, v. 14, n. 40, p. 35-50, jan./abr. 2009.

ALVES-MAZZOTTI, Alda Judith. Representações sociais: aspectos teóricos e aplicações à educação. Em aberto. Brasília-DF, v. 14, n. 61, p. 60-78, jan./mar. 1994. ANICETO, Rosimere de Almeida. Entre discursos e práticas nos ciclos de aprendizagem: as representações sociais dos professores. 2011. 282 f. Dissertação (Mestrado em Educaçãol - Programa de Pós-Graduação, Universidade Federal de Pernambuco, 2011.

LIMA, Andreza Maria de. 0 "bom aluno" nas representações sociais de professoras da rede municipal de ensino do Recife. 2009. 379 f. Dissertação (Mestrado em Educação) - Programa de Pós-Graduação, Universidade Federal de Pernambuco, 2009.

MACHADO, Laêda Bezerra; ANICETO, Rosimere de Almeida. Núcleo central e periferia das representações sociais de ciclos de aprendizagem entre professores. Ensaio: avaliação e políticas públicas em educação. Rio de Janeiro-RJ, v.18, n.67, p.345-363, abr./jun. 2010.

MACHADO, Laêda Bezerra. Eles "passam de bolo" e ficam cada vez mais analfabetos: discutindo as representações sociais de ciclos de aprendizagem entre professores. Revista psicologia da educação. São Paulo-SP, v. 24, p. 111-128. jan./jun. 2007.

MAINARDES, Jefferson. A escola em ciclos: fundamentos e debates. São Paulo-SP: Cortez, 2009.

OLIVEIRA, Denize Cristina de; MARQUES, Sérgio Correia; GOMES, Antônio Marcos; 
TEIXEIRA, Maria Cristina Trigueiro. Análise das evocações livres: uma técnica de análise estrutural das representações sociais. In: MOREIRA, Antônia Silva Paredes; CAMARGO, Brígido Vizeu; JESUÍNO, Jorge Correia; NOBREGA, Sheva Maia. Perspectivas teóricometodológicas em representações sociais. João Pessoa-PB: Editora UFPB, 2005. p. 573-606.

RECIFE, Secretaria de Educação. Diretoria-Geral do Ensino. Tempos de aprendizagem, identidade cidadã e organização da educação escolar em ciclos. Recife-PE: Secretaria de Educação, 2003.

Recebido em abril de 2013

Aprovado em maio de 2013

Laeda Bezerra Machado é professora adjunta do Departamento de Administração Escolar e Planejamento Educacional - Programa de Pós Graduação em Educação - Núcleo de Formação de Professores e Prática Pedagógica Centro de Educação da Universidade Federal de Pernambuco. Email: laeda01Agmail.com

Suelen Batista Freire é estudante de pedagogia pela Universidade Federal de Pernambuco e bolsista PIBIC/FACEPE CNPq. Email: suelenbfreireahotmail.com 